\title{
Desempenho produtivo e qualidade de cultivares de rúcula em sistema semi-hidropônico
}

\author{
Lucimara Lima Jardina ${ }^{1}$, Carlos Alberto Martins Cordeiro ${ }^{1}$, Marcelo Cléon de Castro Silva ${ }^{1}$, \\ Alex Guimarães Sanches², Pedro Vitorino de Araújo Júnior ${ }^{2}$
}

\author{
${ }^{1}$ Universidade Federal do Pará, Campus Bragança, Bragança, Pará, Brasil. E-mail: lucimara.ldm@gmail.com, \\ camcordeiro2006@gmail.com, marcelocleon@ufpa.br \\ ${ }^{2}$ Universidade Federal do Pará, Campus Altamira, Altamira, Pará, Brasil. E-mail: alexsanches.eng@ gmail.com
}

Recebido: 26/12/2016; Aceito: 01/03/2017

\section{RESUMO}

O sistema semi-hidropônico é uma alternativa para a produção de hortaliças; combina substrato inerte e solução nutritiva, requer menor quantidade de água e funciona por nível, não há uso de energia elétrica. Nesse contexto, objetivou-se avaliar o desempenho produtivo e a qualidade de cultivares de rúcula em sistema semi-hidropônico. A pesquisa foi desenvolvida em hidroponia comercial localizada no município de Altamira-PA, no período de dezembro de 2014 a fevereiro de 2015. As cultivares avaliadas foram: Apreciatta, Cultivada, Donatella, Gigante e Rococó. Aos 28 dias após o transplante foram avaliados a altura das plantas, número de folhas, massa fresca das raízes e produtividade; a qualidade foi determinada mediante análises de $\mathrm{pH}$, sólidos solúveis totais (SST), acidez total titulável (ATT) e relação SST/ATT. O delineamento experimental foi em blocos casualizados, utilizando cinco tratamentos, sob a forma de cinco cultivares de rúcula com cinco repetições. A cultivar Apreciatta apresentou maior altura quando comparada às demais, contudo, a cultivar Gigante foi superior no acúmulo de massa fresca das raízes e produtividade. Quanto à qualidade, todas as cultivares apresentaram valores médios dentro do esperado na colheita. A cultivar Gigante apresentou desempenho produtivo superior às demais cultivares no cultivo semi-hidropônico.

Palavras-chave: Eruca sativa Miller; ambiente protegido; produtividade

\section{Productive performance and quality of arugula cultivars in semi-hydroponic system}

\begin{abstract}
The semi-hydroponic system is an alternative for the production of vegetables, by combining inert substrate and nutrient solution requiring less water and by functioning per level, there is no use of electric energy. In this context, the objective was to evaluate the productive performance and quality of arugula cultivars in a semihydroponic system. The research was developed in commercial hydroponics located in the municipality of Altamira-PA in the year 2016. The cultivars evaluated were: Apreciatta, Cultivada, Donatella, Gigante and Rococó. Plant height, leaf number, fresh root mass and yield were evaluated at 28 days after transplanting. The $\mathrm{pH}$ was determined by $\mathrm{pH}$, total soluble solids (TSS), total titratable acidity (ATT) and SST / ATT. The experimental design was in randomized blocks, using five treatments, in the form of five cultivars of arugula with five replicates. The cultivar Apreciatta presented higher height when compared to the others, however, the cultivar Gigante was superior in the variables fresh mass of the roots and productivity. Regarding quality, all cultivars presented average values within the expected harvest. The cultivar Gigante presented superior productive performance to the other cultivars in the semi-hydroponic
\end{abstract}

Key words: Eruca sativa Miller; protected environment; productivity. 


\section{Introdução}

A rúcula (Eruca sativa Miller) é uma hortaliça herbácea, pertencente à família das Brassicáceae, originária da região Mediterrânea e oeste da Ásia. Destaca-se entre as hortaliças folhosas pela sua composição, com altos teores de potássio, enxofre, ferro, vitaminas A e C, pelo sabor picante e odor agradável (GENUNCIO et al., 2011).

De acordo com Machado et al. (2011), esta hortaliça pode ser cultivada em ambiente protegido e tal forma de cultivo tem se expandido praticamente em todas as regiões do Brasil. Para Costa et al. (2011), essa técnica oferece uma série de vantagens, como a possibilidade de controle total ou parcial das condições climáticas que possam prejudicar o crescimento e o desenvolvimento da cultura tais como temperatura, umidade do ar, radiação solar e vento. A técnica favorece, assim, melhor desenvolvimento das hortaliças, permitindo melhor eficiência produtiva e consequente qualidade dos produtos.

Com a alta demanda na produção de hortaliças, Alves et al. (2012) destacaram a necessidade no aprimoramento de técnicas que possibilitem a obtenção de um produto de melhor qualidade, interferindo em modificações importantes nos sistemas de produção de hortaliças. Alguns dos sistemas utilizados para o cultivo de hortaliças são o convencional, hidropônico e semihidropônico, que apresentam características diferenciadas na produção, podendo influenciar nas propriedades da hortaliça.

Os sistemas de cultivo convencional em uso no Brasil, segundo Souza e Garcia (2013), caracterizam-se pelo elevado uso de fertilizantes minerais, o que provoca aumento expressivo nos custos de produção e grande dependência dos diversos fatores do mercado. Com o passar do tempo, o uso excessivo de fertilizantes, provoca uma redução na atividade biológica do solo o que afeta diretamente o desempenho produtivo das culturas. Além disso, o sistema convencional deixa o solo mais susceptível ao processo de erosão (PANACHUKI et al., 2011).

Por sua vez, o sistema hidropônico, segundo Luz et al. (2011) é a ciência de cultivar plantas sem solo; as raízes recebem uma solução nutritiva balanceada que contém água e todos os nutrientes essenciais ao desenvolvimento da planta, o que facilita um controle mais adequado da nutrição da hortaliça produzida. Apesar de ser um sistema considerado caro nos primeiros anos de implantação, possibilita melhor comodidade ao trabalho e pode também ser implantado em pequenas áreas.

De acordo com Wendling et al. (2005), o sistema semi-hidropônico é uma alternativa para a produção de hortaliças pois não é necessário o uso de energia elétrica funcionando por nível. A quantidade de água consumida é bem menor se comparada ao sistema convencional pois este sistema faz uso de solução nutritiva em conjunto com substrato sólido inerte (areia, fibra de coco) que mantém a umidade nas calhas sendo de suma importância para o crescimento e desenvolvimento das plantas.

Em função do exposto, o presente trabalho teve como objetivo avaliar o desempenho produtivo e a qualidade de cultivares de rúcula em sistema de cultivo semi-hidropônico, nas condições de Altamira-PA.

\section{Material e Métodos}

A pesquisa foi desenvolvida em hidroponia comercial, localizada no município de Altamira-PA (0313'54', S, 52 ${ }^{\circ} 13^{\prime}$ '55', W e altitude média de $\left.104 \mathrm{~m}\right)$, onde as condições climáticas foram as seguintes: temperatura média de $27,3{ }^{\circ} \mathrm{C}$, com temperaturas máximas e mínimas de 32,4 e $22,1{ }^{\circ} \mathrm{C}$, respectivamente, e umidade relativa média do ar de $80,4 \%$, em sistema de cultivo semi-hidropônico no período compreendido entre dezembro de 2014 e fevereiro de 2015.

O delineamento experimental foi em blocos casualizados, utilizando cinco tratamentos constituídos de cinco cultivares de rúcula com cinco repetições. Utilizou-se as cultivares: Apreciatta, Cultivada, Donatella, Gigante e Rococó.

A semeadura foi realizada no dia 14 de dezembro, em placas de espuma fenólica, sendo acondicionadas em bandejas de polietileno, onde colocou-se 12 sementes por célula. $\mathrm{O}$ desbaste foi realizado no décimo dia após a semeadura, deixando-se quatro plantas por célula.

O transplantio das mudas para as calhas com sistema semi-hidropônico foi realizado por meio de plantio direto, em substrato formado pela mistura de fibra de coco com a solução nutritiva. Sistema composto por sete canais de cultivo (tubos de polipropileno), com $4 \mathrm{~m}$ de comprimento, distanciados a cada $10 \mathrm{~cm}$ e com espaçamento de $15 \mathrm{~cm}$ entre plantas, sendo avaliadas as cinco fileiras centrais.

No preparo da solução nutritiva foi utilizado um coquetel de sais para hidroponia adquirido da empresa Hidrogood: Horticultura moderna, o qual é recomendado para a produção de hortaliças folhosas. Foram preparados 1000 L de solução nutritiva, utilizando-se $750 \mathrm{~g}$ de composto Hidrogood Fert ${ }^{\circledR}+600$ $\mathrm{g}$ nitrato de cálcio $+30 \mathrm{~g}$ ferro $(\mathrm{Fe})$.

No decorrer do experimento, as plantas foram irrigadas manualmente duas vezes ao dia com o auxílio de um irrigador, procurando manter as tensões de água no substrato sempre próximas a capacidade de vaso e a saturação máxima de modo a satisfazer as necessidades hídricas da cultura nesse estádio. A colheita foi realizada 28 dias após o transplantio, sendo determinada em função do tamanho comercial $(15-20 \mathrm{~cm})$. 
Avaliou-se a altura de planta, com a ajuda de uma régua, a partir do nível do solo até a extremidade das folhas; foram avaliados número de folhas, massa fresca das raízes - determinada a partir da pesagem em balança analítica -, e a produtividade. Para as características de qualidade, logo após a colheita determinou-se: o teor de sólidos solúveis totais (SST) - medido pelo índice de refração em refratômetro portátil -; a acidez titulável total (ATT) através de reação de neutralização com $\mathrm{NaOH} 0,1 \mathrm{~N}$ e fenolftaleína como solução indicadora; o $\mathrm{pH}$ por meio de leitura direta no suco através de pHmetro previamente calibrado e a relação (SST/ATT).

Os dados foram submetidos à análise de variância com o auxílio do programa estatístico ASSISTAT, versão 7.7 beta (2014). As médias dos tratamentos foram comparadas aplicando-se o Teste de Tukey ao nível de 5\% de probabilidade

\section{Resultados e Discussão}

Os resultados da análise de variância evidenciaram que houve diferenças significativas entre as cultivares para as variáveis altura de planta $(\mathrm{p}=0,01)$, massa fresca das raízes $(\mathrm{p}=0,01)$ e produtividade $(\mathrm{p}=0,05)$ (Tabela 1$)$.

As cultivares Apreciatta e Gigante apresentaram os maiores valores de altura de planta comparado as outras cultivares (Tabela 2). A altura de planta obtida neste trabalho, foram superiores aos encontrados por Linhares et al. (2011), que avaliando o efeito da adubação verde com jitirana incorporada ao solo, constataram valores de altura de planta de 21,0 e $20,0 \mathrm{~cm}$, para as cultivares Cultivada e Folha Larga, respectivamente. Ao avaliar o consórcio e monocultivo de rúcula, Rezende et al. (2006) obtiveram valores de altura semelhantes, com média de 25,95.
Quanto ao número de folhas não foi observada diferença significativa entre as cultivares, variando entre 19,0 a 22,8 para Donatella e Apreciatta, respectivamente (Tabela 2). Porto et al. (2013) constataram que a adubação potássica não afetou significativamente $o$ número de folhas de cultivares de rúcula. Avaliando a produção de rúcula em diferentes densidades de plantas, Lima et al. (2013) constataram valores de 11,9 e 16,9 folhas por planta. Avaliando duas cultivares de rúcula irrigadas com águas salinas em Mossoró, Oliveira et al. (2012) observaram médias entre 15,3 a 16,1. Freitas et al. (2009) analisando o desempenho agronômico obtiveram valores de 8,81 e 13,30 na rúcula Cultivada em função de diferentes espaçamentos.

Estes resultados inferiores aos obtidos neste estudo evidencia que o cultivo semi-hidropônico em ambiente protegido possibilita boas condições para o desenvolvimento das cultivares. Para Alves et al. (2012) a avaliação da quantidade de folhas por planta é de extrema importância, por ser a parte da planta mais avaliada pelo consumidor no momento da compra da hortaliça.

Analisando a variável massa fresca das raízes observa-se que as cultivares Gigante, Cultivada e Rococó apresentaram valores superiores às demais cultivares (Tabela 2). O tamanho do sistema radicular influencia diretamente na capacidade de absorção dos nutrientes para as plantas, portanto, quanto maior for as raízes, maior será a possibilidade da mesma em absorver os nutrientes necessários para o seu adequado desenvolvimento. Para Prado (2008), a absorção é influenciada por fatores externos e internos, ligados a própria plantas, que podem modificar a velocidade de absorção, podendo alterar sua eficiência.

Tabela 1: Resumo da análise para as variáveis altura da planta, número de folhas (NF), massa fresca das raízes (MFR) e produtividade das diferentes cultivares de rúcula em sistema semi-hidropônico.

\begin{tabular}{lccccc}
\hline \multirow{2}{*}{ Fontes de Variação } & \multirow{2}{*}{ G.L } & \multicolumn{4}{c}{ Quadrado Médio } \\
\cline { 3 - 6 } & & Altura & NF & MFR & Produtividade \\
\hline Blocos & 4 & $15,47^{* *}$ & $2,38^{\text {ns }}$ & $0,30^{\text {ns }}$ & $6,20^{* *}$ \\
Tratamentos & 4 & $8,96^{* *}$ & $1,60^{\text {ns }}$ & $8,41^{* *}$ & $4,02^{*}$ \\
Resíduos & 16 & 4,16 & 5,86 & 0,87 & 3,43 \\
\hline CV\% & 24 & 9,43 & 11,62 & 20,36 & 12,31 \\
\hline
\end{tabular}

** significativo ao nível de $1 \%$ de probabilidade; *significativo ao nível de $5 \%$ de probabilidade; ns = não significativo $(\mathrm{p}>0,05)$.

Tabela 2: Médias e desvio padrão sobre as variáveis: altura de planta, número de folhas (NF), massa fresca das raízes (MFR) e produtividade de cultivares de rúcula em sistema semi-hidropônico.

\begin{tabular}{lcccc}
\hline Cultivares & Altura $(\mathrm{cm})$ & NF & MFR $(\mathrm{g})$ & Produtividade (mg/ha) \\
\hline Apreciatta & $26,0 \pm 4,8 \mathrm{a}$ & $22,8 \pm 2,32 \mathrm{a}$ & $3,12 \pm 0,24 \mathrm{~b}$ & $15,2 \pm 2,1 \mathrm{ab}$ \\
Cultivada & $18,8 \pm 2,5 \mathrm{~b}$ & $20,8 \pm 2,93 \mathrm{a}$ & $5,54 \pm 1,36 \mathrm{a}$ & $13,1 \pm 1,8 \mathrm{~b}$ \\
Donatella & $18,4 \pm 1,7 \mathrm{~b}$ & $19,0 \pm 1,67 \mathrm{a}$ & $3,61 \pm 0,45 \mathrm{~b}$ & $14,1 \pm 3,6 \mathrm{ab}$ \\
Gigante & $25,0 \pm 3,8 \mathrm{a}$ & $21,2 \pm 2,56 \mathrm{a}$ & $5,95 \pm 0,94 \mathrm{a}$ & $17,6 \pm 1,0 \mathrm{a}$ \\
Rococó & $20,0 \pm 4,2 \mathrm{~b}$ & $20,4 \pm 2,58 \mathrm{a}$ & $4,80 \pm 0,43 \mathrm{ab}$ & $15,2 \pm 2,5 \mathrm{ab}$ \\
\hline
\end{tabular}

Médias seguidas da mesma letra na coluna não diferem estatisticamente entre si pelo teste de Tukey $(\mathrm{p}<0,05)$. 
Com relação à produtividade, a cultivar Gigante apresentou melhores resultados com média de 17,60 mg/há, diferindo estatisticamente da Apreciatta, Rococó e Donatella, com 15,19, 15,19 e 14,13, respectivamente (Tabela 2). A superioridade demonstrada para a cultivar Gigante pode ser explicada pelo fato de a mesma apresentar quantidade de raiz superior às demais sendo que este órgão está diretamente relacionado à absorção de nutrientes pela planta.

De acordo com Prado (2008), a produtividade é o fator principal para determinar o lucro de um empreendimento agrícola. Desta forma, é necessário que a cultura trabalhada seja bem nutrida pois a produção é determinada diretamente pelo estado nutricional da planta.

Os resultados da análise de variância para as variáveis $\mathrm{pH}$, sólidos solúveis totais, acidez total titulável e relação SST/ATT das amostras das cultivares de rúcula estão na Tabela 3 . Verifica-se que houve diferença significativa apenas para a variável $\mathrm{pH}$ á nível de $5 \%$ entre as cultivares.

Em relação aos diferentes tipos de cultivares os valores apresentaram diferença apenas nos valores de $\mathrm{pH}$ onde a maior média verificada foi no cultivar Rococó de 6,81. Os teores de acidez não diferiram entre os cultivares avaliados com médias oscilando entre 0,30 a 0,34 g. ácido málico (Tabela 4), caracterizando as amostras com um sabor bem ácido se comparado aos valores encontrados por Campos et al. (2013) cujo teor de acidez na polpa de rúculas oscilou entre 0,040 e 0,050 .

Ainda de acordo com a Tabela 4, observa-se que não foi verificada interação sobre o teor de sólidos solúveis totais (açucares) com valores variando de 3,45 a 3,54 ${ }^{\circ}$ Brix entre as cultivares. $O$ índice de maturação expresso pela relação SST/ATT (Tabela 4) mostrou que não houve interação significativa entre as cultivares, indicando, portanto, que todas apresentavam uma boa relação entre a quantidade de açucares e de ácidos orgânicos no momento da colheita favorecendo sua caracterização organoléptica de aceitação pelo consumidor final.

Ainda de acordo com a Tabela 4, as amostras de rúculas atingiram um $\mathrm{pH}$ de 5,81, ATT de 0,34 g de ácido málico e teor de SST de 3,74, valores significativamente menores em relação aos obtidos por Vasconcelos et al. (2011), que apresentaram um pH de 5,86, ATT de 0,37 g de ácido málico e SST de 4,92 Brix em amostras de rúculas cultivadas no sistema convencional, evidenciando que o sistema de cultivo semi-hidropônico contribui nas características do metabolismo após a colheita.

Tabela 3: Resumo da análise de variância para as variáveis pH, sólidos solúveis totais (SST), acidez total titulável (ATT) e relação SST/ATT das cultivares de rúcula em sistema semi-hidropônico.

\begin{tabular}{|c|c|c|c|c|c|}
\hline \multirow[t]{2}{*}{ Fontes de Variação } & \multirow{2}{*}{ GL } & \multicolumn{4}{|c|}{ Quadrado Médio } \\
\hline & & $\mathrm{pH}$ & SST & ATT & SST/ATT \\
\hline Blocos & 4 & $7,01 * *$ & $2,28^{\mathrm{ns}}$ & $0,83^{\mathrm{ns}}$ & $1,99^{\mathrm{ns}}$ \\
\hline Tratamentos & 4 & $3,37 *$ & $3,98^{\mathrm{ns}}$ & $2,09^{\mathrm{ns}}$ & $0,05^{\mathrm{ns}}$ \\
\hline Resíduos & 16 & 0,05 & 0,05 & 0,06 & 0,12 \\
\hline $\mathrm{CV} \%$ & 24 & 1,29 & 6,41 & 8,01 & 5,24 \\
\hline
\end{tabular}

** significativo ao nível de $1 \%$ de probabilidade; *significativo ao nível de 5\% de probabilidade; ns não significativo (p >= 0,05 ).

Tabela 4. Médias e desvio padrão sobre os teores de pH, acidez total titulável (ATT), sólidos solúveis totais (SST) e relação SST/ATT em cultivares de rúcula produzidas em sistema semi-hidropônico.

\begin{tabular}{lcccc}
\hline \multicolumn{1}{c}{ Cultivares } & $\mathrm{pH}$ & ATT $(\mathrm{g}$ ác. málico) & SST $\left({ }^{\circ}\right.$ Brix $)$ & ATT/SST \\
\hline Apreciatta & $5,70 \pm 1,23 \mathrm{a}$ & $0,32 \pm 0,15 \mathrm{a}$ & $3,49 \pm 1,26 \mathrm{a}$ & $6,77 \pm 1,56 \mathrm{a}$ \\
Cultivada & $5,66 \pm 0,89 \mathrm{a}$ & $0,30 \pm 0,21 \mathrm{a}$ & $3,45 \pm 1,19 \mathrm{a}$ & $6,83 \pm 1,44 \mathrm{a}$ \\
Donatella & $5,67 \pm 0,67 \mathrm{a}$ & $0,31 \pm 0,18 \mathrm{a}$ & $3,51 \pm 1,28 \mathrm{a}$ & $6,81 \pm 1,63 \mathrm{a}$ \\
Gigante & $5,70 \pm 0,86 \mathrm{a}$ & $0,33 \pm 0,16 \mathrm{a}$ & $3,45 \pm 1,23 \mathrm{a}$ & $6,81 \pm 1,51 \mathrm{a}$ \\
Rococó & $5,81 \pm 1,03 \mathrm{~b}$ & $0,34 \pm 0,17 \mathrm{a}$ & $3,54 \pm 1,19 \mathrm{a}$ & $6,74 \pm 1,39 \mathrm{a}$ \\
\hline CV $(\%)=$ & 0,89 & 1,56 & 1,28 & 2,94 \\
\hline
\end{tabular}

Médias seguidas da mesma letra na coluna não diferem estatisticamente entre si pelo teste de Tukey $(\mathrm{p}<0,05)$

\section{Conclusões}

O sistema semi-hidropônico mostrou-se eficiente para o crescimento e desenvolvimento das plantas de rúcula, alcançando altos índices de produção.
A cultivar Gigante apresentou desempenho produtivo superior às demais cultivares, sendo a mais indicada para o cultivo em sistema semi-hidropônico.

A qualidade das cultivares foi influenciada somente pelos teores de $\mathrm{pH}$ no momento da colheita. 


\section{Referências Bibliográficas}

ALVES, R. F.; LINHARES, P. C. F.; PEREIRA, M. F. S.; FILHO, J. L.; SOUSA, A. J. P.; PAIVA, A. C. C. Desempenho agronômico da rúcula sob diferentes proporções de jitirana e flor-de-seda em sistema orgânico. Revista Agropecuária Científica no Semi-Árido. Campina GrandePB, v. 8, n. 4, p.107-112, 2012.

CAMPOS, B. O.; OSHIRO, V. S.; AYD, M. Avaliação química de rúcula de diferentes procedências. Revista Interbio, Campo Grande, MS, v.7, n. 2, p. 54-60, 2013.

COSTA, C. M. F.; SEABRA JÚNIOR, S.; ARRUDA, G.R.; SOUZA, S. B. S. Desempenho de cultivares de rúcula sob telas de sombreamento e campo aberto. Semina: Ciências Agrárias. Londrina-PR, v. 32, n. 1, p. 93-102, 2011.

FREITAS, K. K. C.; BEZERRA NETO, F.; GRANGEIRO, L. C.; LIMA, J. S. S.; MOURA, K. H. S. Desempenho agronômico de rúcula sob diferentes espaçamentos e épocas de plantio. Revista Ciência Agronômica. Fortaleza-CE, v. 40, n. 4, p. 449-454, 2009.

GENUNCIO, G. C.; SILVA, R. A. C.; SÁ, N. M.; MARY, W.; ZONTA, E. Produtividade de rúcula hidropônica cultivada em diferentes épocas e vazões de solução nutritiva. Horticultura Brasileira, Brasília-DF, v. 29, n. 2, p. 605-608, 2011.

LINHARES, P. C. F.; MARACAJÁ, P.B.; BEZERRA, A. K. H.; PEREIRA, M. F. S.; PAZ, A. E. S. Rendimento de cultivares de rúcula adubado com diferentes doses de (Merremia aegyptia L). Revista Verde de Agroecologia e Desenvolvimento Sustentável. Pombal-PB, v. 6, n. 1, p. 07$12,2011$.

LUZ, J. M. Q.; COSTA, C. C.; GUERRA, G. M. P.; SILVA, M. A. D.; HABER, L. L. Efeito da variação da solução nutritiva no cultivo hidropônico de rúcula. Revista Verde de Agroecologia e Desenvolvimento Sustentável. Pombal-PB, v. 6, n. 3, p.76-82, 2011.

MACHADO, F. F.; NOVACK, M. M. E.; NÖRNBERG, J. L.; COLPO, E. Análise de frações de fibra alimentar em rúcula e alface em diferentes estágios de maturação, sob sistema hidropônico. Alimentos e Nutrição. Araraquara-SP, v. 3, n. 2, p. 401-406. 2011.
OLIVEIRA, F. A.; OLIVEIRA, M. K. T.; SOUZA NETA, M. L.; SILVA, R. T.; SOUZA, A. A. T.; SILVA, O. M. P.; GUIMARÃES, I. P. Desempenho de cultivares de rúcula submetidas a diferentes níveis de salinidade da água de irrigação. Agropecuária Científica no Semiárido, PombalPB, v. 8, n. 3, p. 67-73, 2012.

PANACHUKI, E.; BERTOL, I.; SOBRINHO, T. A.; OLIVEIRA, P. T. S; RODRIGUES, D. B. B. Perdas de solo e de água e infiltração de água em Latossolo Vermelho sob sistema de manejo. Revista Brasileira de Ciência do Solo, Viçosa, MG, v. 35, n. 5, p. 1777-1785, 2011.

PORTO, R. A.; SILVA, E. M. B.; SOUZA, D. S. M.; CORDOVA, N. R. M.; POLYZEL, A. C.; SILVA, T. J. A. Adubação potássica em plantas de rúcula: produção e eficiência no uso da água. Revista Agro@mbiente, Boa Vista-RO, v. 7, n. 1, p. 28-35, 2013.

PRADO, R. M. Absorção Iônica Radicular: Fatores internos e externos que afeta a absorção de nutrientes pela raiz. In: PRADO, R M. (Ed.). Nutrição de Plantas. 1. ed. São PauloSP: UNESP. p. 58. 2008.

REZENDE, B. L. A.; CECÍLIO, F. A. B.; FELTRIM, A. L.; COSTA, C. C.; BARBOSA. J. C. Viabilidade da consorciação de pimentão com repolho, rúcula, alface e rabanete. Revista Horticultura Brasileira, Brasília-DF, v. 24, n. 1, p. 36-41, 2006.

SOUZA, J. L.; GARCIA, R. D. C. Custos e rentabilidades na produção de hortaliças orgânicas e convencionais no estado do espírito santo. Revista Brasileira de Agropecuária Sustentável, Viçosa-MG, v. 3, n. 1, p.11-24, 2013.

VASCONCELOS, R. L.; FREITAS, M. P. N.; BRUNINI, M. A. Características físico-químicas da Rúcula $\mathrm{CV}$. cultivada produzida no sistema convencional e no baby leaf. Revista Nucleus, Ituverava-SP, v. 8, n. 2, p. 7-14, 2011.

WENDLING, I.; FERRARI, M. P.; DUTRA, L. F. Produção de mudas de corticeira-do-mato por miniestaquia a partir de propágulos juvenis. Colombo-PR: Embrapa Florestas, 2005. 5p. (Comunicado Técnico, 130). 